\title{
O ensino do design de moda: o uso da moulage como ferramenta pedagógica
}

Jonathan Gurgel de Lima'

Isabel Cristina Italiano'

\section{Resumo}

0 presente artigo discute questões referentes ao papel da educação formal no desenvolvimento do potencial criativo de jovens profissionais. Com enfoque na formação universitária em design de moda, aponta as possíveis causas para a desmotivação dos alunos quando deparados com as disciplinas que envolvem práticas de criatividade. É percebido que, além das dificuldades técnicas para expressar as ideias do projeto, há também entraves em relação à não exigência de resultados predefinidos. Tomando como base os estudos de pesquisadores que atribuem às causas do bloqueio criativo dos alunos a uma formação educacional formal estagnada e que pouco privilegia o desenvolvimento humano, o texto levanta a hipótese do uso de uma ferramenta que, embora comum ao cotidiano dos profissionais da área de moda, ainda é pouco explorada em seu pleno potencial. Trata-se do manequim de moulage, mais comumente usado para a concepção de moldes de vestuário em três dimensões. Este artigo defende que o processo criativo, fazendo uso das técnicas de moulage, possui potencialidades pouco exploradas que podem contribuir para o aprimoramento do ensino do design de moda, desenvolver o potencial criativo, motivar o aprendizado, bem como servir de alternativa para a expressão de ideias em vestuário. Apresentam-se neste trabalho o conteúdo e os resultados de uma atividade de criação em moulage desenvolvida com o intuito de experimentar e comprovar as hipóteses aqui levantadas.

\section{Palavras-chave}

Moulage - Educação - Design de moda.

I- Universidade de São Paulo, São Paulo, SP, Brasil.

Contatos: joaopassaromail@gmail.com; isabel.taliano@usp.br 
Fashion design teaching: using draping as a pedagogical tool

Jonathan Gurgel de Lima'

Isabel Cristina Italiano'

\begin{abstract}
This article discusses questions pertaining to the role of formal education in building the creative potential of young professionals. In approaching higher education in fashion, the paper indicates the possible causes of demotivation in students when faced with disciplines involving creative practice. In addition to students' technical difficulties to express their design ideas, another obstacle we found is that students are not required to provide predefined results. Building on studies of researchers that attribute students' creative block to a stagnant formal education that fails to privilege human development, this paper raises the hypothesis that a tool common in fashion professionals' daily practice is still unexplored to its full potential. This tool is draping, which is most commonly used in the creation of fashion molds in three dimensions. We advocate that the use of draping techniques in the creative process has underexplored potentialities which can contribute to enhance fashion design teaching, develop students' creative potential, motivate learning, and serve as an option in expressing ideas for clothing. In this work, we present the content and results of a creation activity using draping, which was conducted with the purpose of testing and verifying the hypotheses raised here.
\end{abstract}

\title{
Keywords
}

Draping - Education - Fashion design.

I- Universidade de São Paulo, São Paulo, SP, Brasil.

Contacts: joaopassaromail@gmail.com;

isabel.italiano@usp.br 


\section{Introdução}

Muito se fala, nos dias de hoje, a respeito da educação do futuro, reflexo de um mundo globalizado com informações em abundância e altíssima velocidade de disseminação. Considerando a conjuntura atual das comunicações, responsáveis por impactantes transformações culturais em todo o globo, tornou-se imprescindivel pensar em mudanças radicais na maneira de educar e preparar os jovens para um contexto que é completamente diferente do qual cresceram os seus pais. Falar em educação do futuro no atual momento, em que as escolas do presente encontram-se, em geral, ainda tão defasadas na sua maneira de educar, pode até ser confundido com uma falta de esperança no presente.

Aparentemente, as instituições de ensino vêm se despertando para essa nova realidade, empenhando esforços na tentativa de se adaptar para, dessa maneira, continuarem existindo. Infelizmente, ainda é muito pouco. Em 2010, Ken Robinson, em mais uma de suas famosas palestras para o TED Talks, chamou a atenção para o fato de que pouco adianta fazer tais mudanças sobre um sistema educacional que já se encontra falido, que não é mais hora para reformas. Para ele, o atual momento pede uma revolução. Novas ações educacionais são demandas imediatas, precisam ser pesquisadas, experimentadas e assimiladas ao sistema. Trata-se de ações que foquem no desenvolvimento humano e em processos capazes de serem moldados de acordo com a interação dos indivíduos, respeitando as características singulares de cada um.

Uma das questões mais levantadas por pesquisadores da área de educação diz respeito ao impacto desumano da atual estrutura educacional, que se assemelha a uma verdadeira linha de montagem fabril, em que cada saber é compartimentalizado e cada aprendizado termina quando o outro começa. Edgar Mourin, também um dos mais respeitados pesquisadores do assunto, critica avidamente o sistema educacional formal, que perdeu o seu lado humanista, focando-se na formação exclusiva de mão de obra especializada para o mercado de trabalho, tratando todos os jovens como uma massa de futuros operários, distanciando-os dos indivíduos de infinito potencial que são (MOURIN, 2003).

Com as constantes mudanças tecnológicas e seus impactos no mercado (e consequentemente no mundo), os profissionais do presente e do futuro precisam, mais que tudo, estarem em plenitude com suas capacidades de aprendizado, para que possam adequar-se, diariamente, às novas demandas. É preciso educar seres humanos capazes de pensar e desenvolver conhecimento, pessoas criativas.

0 perfil do aluno ingressante nos cursos universitários que demandam criação, como é o caso do design de moda, geralmente é de elevado potencial criativo. Apesar de, em sua grande maioria, essas pessoas terem tido o mesmo tipo de educação castradora da criatividade e da individualidade, que foca na promoção do maior número de alunos para o ensino universitário, é possível afirmar que encontraram em seu percurso de vida outros caminhos que as levaram a desenvolver esse potencial.

Muitos aspirantes a profissionais da área de moda tendem a se frustrar quando, nas disciplinas de criação, são confrontados com a necessidade de traduzirem suas ideias por meio do desenho, técnica esta que demanda anos de prática e que poucos alunos dominam.

Seja como for, quando o desenho tira do intelecto a invenção de alguma coisa, precisa que a mão, mediante o estudo e o exercício de muitos anos, esteja apta a desenhar e a exprimir bem qualquer coisa criada pela natureza, seja com pena, estilo, carvão, grafite ou outra coisa. (VASARI, 2006, p. 20).

Alunos que não conseguem desenvolver habilidades básicas para o desenho, a tempo de acompanhar as disciplinas de criação, terminam 
desmotivando-se em relação à área criativa, acreditando que não são aptos. Esses estudantes têm o seu processo criativo prejudicado por uma dificuldade de questão técnica, para a qual é dada demasiada relevância nos cursos universitários de moda. Tendo esse panorama em vista, faz-se necessário pensar em outras técnicas, além do desenho, que possam auxiliar esse aluno a expressar de forma satisfatória o seu potencial criativo, para que a prática possa levá-lo ao aprimoramento das suas ideias e para que o processo criativo contribua para o seu desenvolvimento e não, como na questão levantada, funcione como um entrave pessoal.

Ainda em relação à criação do produto de vestuário, faz-se profundamente necessário o conhecimento técnico sobre as etapas e procedimentos da construção do produto, como em qualquer outra área do design. Esse conhecimento é imprescindivel para que haja coerência e precisão no momento de criar. Alexander McQueen relatou: "eu passei um longo tempo aprendendo como construir roupas, o que é importante fazer antes de desconstruí-las" (BOLTON, 2011, p.30), e, antes dele, Cristobal Balenciaga afirmou que "um costureiro tem de ser um arquiteto para o corte, um escultor para a forma, um pintor para as cores, um músico para a harmonia e um filósofo para o estilo" (SEELING, 2000, p. 214). Pode-se perceber nos discursos desses dois renomados estilistas a confırmação de que o conhecimento consiste em um dos pilares da criação.

Dentre as ferramentas que acompanham a formação de um designer de vestuário, o manequim de moulage ${ }^{1}$ configura-se em um objeto de enorme potencial no que se refere ao desenvolvimento criativo e técnico desse profissional, pois, além de servir como instrumento para o desenvolvimento de moldes de vestuário em três dimensões, também pode ser usado como meio para a criação

1- A moulage, draping ou modelagem tridimensional consiste em uma técnica especial usada para o desenvolvimento de artigos de vestuário a partir do trabalho do tecido em plataforma de três dimensões. Essa técnica possibilita uma melhor visualização da construção dos moldes, criados diretamente sobre manequins que imitam a silhueta humana. de peças, processo no qual o designer vai desenvolvendo suas ideias, enquanto manipula, diretamente sobre o manequim, um material de comportamento semelhante ao da roupa que se objetiva criar.

0 enfoque do programa didático do ensino de moulage nos cursos de graduação na área de moda é, quase sempre, na aplicação de técnicas de modelagem (fazer uso do manequim como plataforma para o desenvolvimento de moldes de peças pré-idealizadas). 0 processo criativo em moulage é comumente menos explorado, ainda de maneira empírica, e pouco precisa.

Ao se fazer uso da moulage no momento de criação, é possível perceber certa variação nos processos convencionais que englobam o design de vestuário de moda contemporâneo, estabelecendo-se uma nova configuração: o designer cria ao mesmo tempo em que modela, podendo assim testar várias possibilidades a partir do que é visualizado em termos de forma e caimento.

\begin{abstract}
Silveira corrobora com a ideia da utilização da modelagem tridimensional como instrumento de criação, quando afirma que a técnica se destaca como ferramenta que permite criar sobre o corpo, dando novas formas e novos significados aos elementos que vão formar o vestuário, sendo introduzida no processo de criação/ produção de moda, como opção para a diferenciação e sucesso do produto. (SILVEIRA apud SOUZA, 2006, p. ?).
\end{abstract}

A interatividade existente entre criador e criação é o foco desse processo criativo que envolve a moulage. 0 designer de moda, nesse caso, terá maior controle sobre o seu projeto, havendo a possibilidade de expandir os seus limites, pois cabe a ele dar forma a suas próprias ideias. Em geral, na atualidade, o processo de modelagem fica a cargo de um modelista, que tem o papel de interpretar o desenho do estilista. Neste caso, se o modelista não tiver nenhuma referência para seguir, é possível 
que demande bastante tempo até alcançar o resultado desejado pelo criador.

Outro ponto bastante instigante no que se refere à moulage é que o simples acaso de se usar um tecido diferente ou aplicá-lo em uma posição não convencional, poderá acarretar resultados completamente surpreendentes, distintos dos definidos inicialmente. Wolf, em seu livro The art of manipulating fabric, comenta que:

Uma técnica aplicada ao peso e maleabilidade da musselina usada neste livro pode estar errada para o tecido em sua mão. No entanto, o tecido poderia transformar uma técnica em algo especial, ou você poderia gerenciar uma fusão incomum de tecido e técnica para um resultado inesperado e único. (WOLF, 1996, p. 8).

Com o passar do tempo, o designer de moda que faz uso da moulage em seu processo criativo pode, por meio do aprimoramento gradual de suas técnicas, descobrir formas de inovar na construção da silhueta da roupa e, inclusive, desenvolver um estilo autoral de manipular o tecido. Nakamichi (2011, p. 104) observa que:

[...] com moldes, há sempre mais do que os olhos podem ver, e dar forma a uma peça de roupa depois de compreender os mecanismos em jogo é uma experiência ainda mais profunda.

\section{Interações possiveis entre criação em moulage, moda e arte}

Levando-se em consideração que nem toda roupa é moda, bem como o termo moda não é aplicado tão somente a itens de vestuário, pode-se interpretar o ato de se criar peças de roupas enquanto se modela instintivamente a matéria-prima sobre o manequim como uma experiência sensorial refinada, assim como um procedimento artístico que possibilita ao designer ter exprimida a sua personalidade criativa sobre a silhueta corporal, resultando dessa criação uma peça de vestuário. 0 desejo de inovar é uma característica pulsante no mundo das artes e também no da moda. Portanto, pode-se pressupor que esses campos tenham tantas interações entre si, podendo, até, coexistirem em um mesmo objeto.

Jimenez (1999, p.36) conclui que:

[...] a obra de arte evidencia-se, portanto, como uma concretização efetiva do poder demiúrgico do artista, capaz de engendrar objetos inéditos que não se reduzem a simples imitação de coisas já existentes.

Suassuna (1975) salienta três momentos importantes para a criação artística. Para o pesquisador:

Para entendermos bem a verdadeira natureza das regras da arte, temos de verificar que a criação artística, una em si mesma, reparte-se, porém, por três campos, três momentos de importância crescente: o campo do oficio, o da técnica e o da forma, este último tomado no sentido filosófico e que é estreitamente ligado à imaginação criadora (SUASSUNA, 1975, p. 225).

Tomando como base essa afirmativa, analisar-se-á a moulage sob a perspectiva desses três campos: ofício, técnica e forma, baseando-se também em estudos de caráter prático realizados pelo autor deste trabalho.

Suassuna (1975, p. 225) explica que "o ofício é a parte mais modesta, mais ligada aos materiais de cada arte. Nesse campo, as regras são universais, válidas e indiscutíveis para todos os artistas”. Na moulage, é preciso que o designer tenha pleno conhecimento que os resultados de seu trabalho estarão diretamente ligados à matéria-prima escolhida. Fluidez, elasticidade, largura e comprimento serão fatores que influenciarão diretamente nos resultados, pois cada tipo de tecido possui 
suas limitações e também suas qualidades específicas.

Num grau superior ao do ofício, está a técnica. É uma espécie de ofício mais vivo, menos rígido, mais espiritualizado. Aí, as opções do artista já são mais livres; as regras da arte ainda existem, mas já são bastante mais abertas. (SUASSUNA, 1975, p. 227).

Existem várias maneiras de se manipular o tecido sobre o manequim, sendo as mais comuns o uso de pregas, recortes, plissados e pences, cabendo ao designer utilizar aqueles com os quais o seu projeto mais se identificar ou os que ele mesmo tiver mais afinidade.

Ainda segundo Suassuna (1975, p. 228), “a alma da arte está essencialmente nesse campo da forma, governado pela imaginação criadora, e, também, apenas de certa forma, na técnica”. No decorrer da criação artística, na moulage, o designer realiza um trabalho bastante instintivo e, quanto mais livre ele se sentir para imprimir sua identidade em seu trabalho, mais autoral será o resultado.

\section{Criação de vestuário de moda em moulage}

Segundo Souza (2006, p. 15),

No intuito de prospectar a indústria do vestuário de moda do futuro, no que tange à área de concepção e desenvolvimento de produto, Agis, Gouveia \&t Vaz (2001) - estudiosos das macrotendências para as indústrias têxtil, vestuário e moda até 2020 - afirmam que o design e a modelagem serão as variáveis estratégicas decisivas para a maior orientação para o mercado, destacando-se como agentes do processo. [...] a moulage pode ser utilizada para diversos fins: para a elaboração de bases de modelagem; para a interpretação e viabilização de modelos já concebidos, em especial os mais complexos; como auxílio à modelagem plana no desenvolvimento de modelos mais elaborados ou ainda como instrumento de criação.

Sendo assim, é possível perceber o quanto é importante a contribuição dessa técnica para o mercado de vestuário.

Para aplicar esse processo à realidade do designer de moda que trabalha em uma cadeia produtiva de larga escala, propõe-se a utilização da moulage ainda no início da pesquisa de tendências, enquanto se está a defınir silhuetas, agregando as ideias colhidas das experimentações ao processo criativo que já é comum a sua rotina de trabalho. Por exemplo, numa situação hipotética em que os anos 1960 sejam um dos conceitos abordados na coleção de um designer, e este decida que sua coleção terá uma silhueta em $A$, a moulage poderá ser utilizada para a experimentação de uma modelagem diferenciada para essa silhueta, que, posteriormente, seria planificada, desenhada e desmembrada em mais peças, construindo famílias compostas de variações daquela mesma modelagem, desenvolvida no experimento anterior.

Um único vestido pode dar origem a blusas, saias e outros vestidos, somente mudando comprimento, retirando-se uma informação ou outra, acrescentando-se uma manga ou retirando-a, somando-se um acessório. A proposta parece algo viável e pode, inclusive, tornar o ambiente de criação mais dinâmico.

É natural pensar que o procedimento de criação em moulage consiste em um processo que, além de demandar mais tempo de execução, promove um maior desperdício de matériaprima. De fato, ele demanda mais tempo, mas, em compensação, o resultado da criação é também o molde e a pré-visualização do protótipo. Quanto ao fator desperdício, a moulage em nada difere da modelagem plana. Uma maior formação de resíduos têxteis será observada no desenvolvimento de peças mais rebuscadas em qualquer procedimento de modelagem de vestuário, principalmente se for necessário o 
uso do fio em viés (diagonal do tecido) para dar melhor caimento e fluidez ao modelo. A criação em moulage pode, inclusive, ser usada como uma maneira de se obter o máximo de aproveitamento da matéria-prima, a exemplo da atividade que será apresentada neste artigo.

\section{A moulage como ferramenta pedagógica}

A proposta deste trabalho é apresentar as vantagens que uma maior atenção e dedicação ao ensino da criação em moulage podem promover no aprendizado de futuros profissionais da área de moda. Conceber peças a partir da moulage, ao mesmo tempo que exercita a criatividade, induz o aprendizado sobre a construção da roupa. A técnica, por possibilitar a visualização prévia do protótipo, estimula o aluno a conhecer mais sobre a matéria-prima e os acabamentos que serão usados na produção da peça final do modelo que eles mesmos criaram e modelaram. Desta maneira, vão sendo motivados a entender mais profundamente sobre os processos que envolvem a sua formação profissional. 0 estímulo vai surgindo de forma natural, como consequência do desenvolvimento pessoal criativo, o que torna o aprendizado mais prazeroso e integrado.

Considerando todas as qualidades referentes ao processo de criação em moulage aqui citadas, os autores deste artigo levantaram alguns procedimentos metodológicos considerados indispensáveis na formulação de práticas desse gênero em sala de aula, favorecendo o melhor aproveitamento da experiência por parte dos alunos e dos próprios ministrantes. Esses aspectos são apresentados a seguir.

Propor um desafio - A proposta do desafio deve ser estimulante, servindo como um gatilho inicial para a criação. 0 intuito não é limitar a criação, que deve ser necessariamente livre, mas fazer com que o participante vá se habituando ao processo enquanto tenta solucionar um problema ou alcançar determinado objetivo.

Contextualizar a proposta por meio de referenciais teóricos e imagéticos - É de grande relevância a apresentação de material referencial antes da prática na moulage, propiciando uma primeira imersão dos participantes no processo criativo que irão exercitar. A demonstração de exemplos proporciona uma familiarização com o procedimento, sendo de grande importância, principalmente, nos primeiros contatos com esse tipo de processo.

Organizar a dinâmica da atividade - Para otimizar os resultados e o tempo da dinâmica, é importante determinar os momentos do processo. A apresentação do material referencial para a prática deve ocupar, no máximo, um terço da atividade. É importante permitir um período de introspecção para os participantes nos primeiros trinta minutos da prática, para só depois fazer interferências, quando necessário. Reservar dez minutos no meio da prática para pedir aos participantes que deem uma pequena pausa em seus projetos e circulem pela sala observando o trabalho dos colegas. Isso ajuda na ampliação do referencial de todos os envolvidos e pode influenciar bastante nos resultados finais da prática. 0 ministrante deve, também, deixar espaço ao fim da atividade para o esclarecimento de dúvidas, bem como promover o diálogo e a troca de conhecimento entre os próprios alunos.

Registrar o processo - Sugerir que os participantes registrem seu processo de criação, por meio de fotografias, enquanto desenvolvem o exercício na moulage. Isso permite que o mesmo possa ir testando diferentes possibilidades de manipular o tecido, sem perder o registro de algo que tenha sido desfeito, ajudando, inclusive, caso o participante deseje refazê-lo.

Acompanhar a atividade - Durante o desenvolvimento das atividades pelos alunos, é importante o acompanhamento do professor/ orientador, com o principal intuito de esclarecer as dúvidas dos participantes e garantir a fluidez do processo. Deve-se evitar qualquer juízo de valor a respeito das criações obtidas. É importante observar a qualidade dos moldes no que se refere a acabamentos, limpeza e coerência com a proposta, mas de forma alguma julgar se um trabalho é mais ou menos criativo. 0 ministrante 
precisa conduzir a atividade de maneira que a experiência seja agradável, respeitando os resultados alcançados por cada participante, ressaltando os pontos positivos e motivando a experimentação.

Discutir os resultados - Como o processo de criação contempla uma grande quantidade de referências pessoais, além de associações de ideias muito particulares, é importante que os participantes apresentem os resultados dos trabalhos para o grupo, abrindo uma possibilidade de justificar suas escolhas e descrever resumidamente seu processo criativo. Para apresentar o desenvolvimento da proposta, cada participante tem de organizar as etapas de seu processo criativo, o que pode levar a uma autoavaliação crítica. Cabe ao ministrante mediar essa etapa de maneira a permitir que todos tenham tempo para falar e que a discussão seja encaminhada de maneira saudável para todo o grupo.

Avaliar a atividade - Pode-se oferecer aos participantes um meio de avaliar a proposta e seus resultados. Com isso, o ministrante avalia a qualidade da atividade e recolhe informações para possíveis alterações e melhorias, em função do perfil do grupo. A sugestão é que seja pedido aos participantes que relatem em algumas linhas de texto, informalmente, um pouco da sua percepção sobre a atividade que acabaram de realizar.

\section{Proposta de atividade}

Com a finalidade de avaliar na prática as hipóteses levantadas neste trabalho, aplicou-se um experimento contemplando os procedimentos metodológicos apontados acima. Foi formatada uma atividade de criação em moulage em forma de workshop a ser desenvolvida com turmas de alunos e ex-alunos de cursos técnicos e de graduação, relacionados ao design de moda. A princípio, o exercício proposto consistia em manipular o tecido cortado em uma forma geométrica pré-definida, forma essa que deveria corresponder ao molde final, sendo o participante instruído para não subtrair nenhum pedaço de tecido enquanto trabalhasse no manequim. Dessa maneira, o participante precisaria criar uma peça de roupa, fazendo uso de drapeados, pregas, fendas, artifícios de manipulação de sua escolha no intuito de encontrar a melhor maneira de solucionar o desafio. No decorrer da aplicação dos workshops foram consideradas necessárias algumas mudanças no processo, considerando o feedback dos participantes. A experiência será apresentada detalhadamente a seguir. 0 título dado para a atividade foi Origamis vestíveis, fazendo referência à técnica oriental de dobraduras em papel. A figura 1 ilustra o processo correspondente à atividade.

Figura 1 - Da esquerda para a direita, etapas do desenvolvimento do molde de uma blusa feminina a partir de um tecido cortado em triângulo.
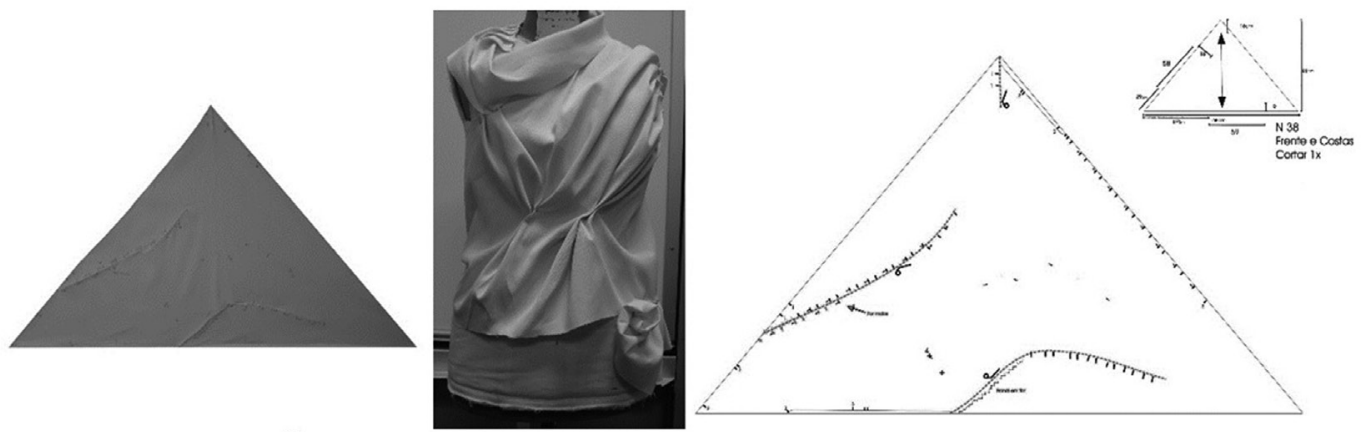

Fonte: Acervo do autor. 
Quadro 1 - Ficha da atividade Origamis vestíveis

\begin{tabular}{|c|c|}
\hline \multicolumn{2}{|r|}{ Ficha de atividade - processos criativos em moulage } \\
\hline Título & Origamis vestíveis \\
\hline Tempo & $\begin{array}{l}\text { Propõe-se uma média de três horas para o exercício, reservando um primeiro momento para a apresentação } \\
\text { de material referencial e o tempo restante para a prática no manequim de moulage. }\end{array}$ \\
\hline Objetivo & $\begin{array}{c}0 \text { participante deve criar uma peça de vestuário na moulage, a partir de um pedaço de tecido em forma } \\
\text { geométrica. }\end{array}$ \\
\hline Material & $\begin{array}{l}\text { Algodão cru de boa qualidade, máquina fotográfica (opcional, para registrar o processo), tesoura, alfinetes } \\
\text { com cabeça, agulha e linha. Suporte: manequim de moulage. }\end{array}$ \\
\hline Desafio & $\begin{array}{l}\text { Os participantes iniciam a prática com um corte de tecido pré-determinado, que corresponde a uma forma } \\
\text { geométrica básica. Esta forma não pode ser alterada durante a criação da peça, sendo permitido que se } \\
\text { façam recortes, contanto que não subtraiam nenhuma parte do tecido. Os alunos são livres para fazerem } \\
\text { qualquer tipo de peça e para manipularem o tecido das maneiras que acharem coerentes. Podem fazer uso } \\
\text { de pences, pregas, franzidos, fendas e amarrações. }\end{array}$ \\
\hline Resultados esperados & $\begin{array}{l}\text { Espera-se que os participantes superem o travamento inicial de não pré-visualizarem suas criações e } \\
\text { consigam desenvolver uma peça inteira na moulage. Ao terminarem, que seja possível retirar a peça do } \\
\text { manequim, sem que haja grandes prejuízos na sua estrutura. Os alfinetes devem funcionar como costuras. }\end{array}$ \\
\hline $\begin{array}{l}\text { Referências a serem } \\
\text { apresentadas }\end{array}$ & $\begin{array}{l}\text { Apresenta-se referencial teórico e visual. Considerando esta atividade como a primeira experiência de } \\
\text { uma turma em criação em moulage, propõe-se discutir a importância e a relevância do uso desta prática } \\
\text { como alternativa para a expressão e criação de peças de vestuário. É interessante apresentar referenciais } \\
\text { bibliográficos que afirmem a capacidade de criar como algo inerente ao ser humano, e seu desenvolvimento } \\
\text { relacionado com a prática. Exemplificar com imagens de trabalhos de estilistas que possuem aderência com } \\
\text { o tema proposto no desafio. } 0 \text { material pode ser apresentado em forma de vídeos, fotos ou ambos. }\end{array}$ \\
\hline
\end{tabular}

Fonte: Elaboração dos autores.

As diretrizes para a aplicação da atividade Origamis vestiveis foram reunidas no Quadro 1.

\section{Aplicação e resultados}

A atividade foi aplicada a 52 alunos, divididos em seis workshops com diferentes quantidades de participantes; a maior turma com dezessete participantes e a menor com quatro. Como o foco da atividade estava no próprio processo criativo, não foi exigido que os participantes tivessem conhecimentos prévios em modelagem de vestuário, tratando-se, em geral, de turmas com conhecimentos básicos. Apenas dois participantes nunca tinham tido contato com nenhuma técnica. Essa amostra possibilitou levantar dados comparativos relevantes para a análise dos resultados deste trabalho.
As atividades iniciaram-se com uma abordagem teórica sobre a criatividade como qualidade inerente a todo ser humano e a importância de ela ser praticada e desenvolvida. Também foram discutidas as condições da educação formal, possuidora de um perfil castrador da criação, e os possíveis reflexos dessa educação na capacidade criativa dos participantes que ali estavam. Após essa introdução, foram propostas as seguintes questões aos participantes: quais deles tinham afınidade com o desenho e o quanto isso influenciava em seu desenvolvimento criativo. Confirmando as hipóteses levantadas pelos autores desta pesquisa, a grande maioria dos participantes confessou não ter boas aptidões para o desenho e sofrer dificuldades em expressar suas ideias por meio de croquis. Muitos participantes, inclusive, já se encontravam em um grau avançado de desmotivação. 
Partindo dessa discussão, abordou-se a moulage como uma alternativa para expor as suas ideias, criando diretamente sobre o manequim e as vantagens desse processo. Para finalizar a parte teórica da atividade, foram apresentados os trabalhos de alguns estilistas que se destacam pelo design inovador de suas peças e pelo trabalho em moulage (Madeleine Vionnet; Alix Grés; Cristobal Balenciaga; Rei Kawakubo; Issey Miyake e Alexander McQueen). A princípio, havia uma preocupação dos autores desta pesquisa de que os participantes poderiam não mostrar interesse na explanação teórica que precede a prática. Porém, ocorreu exatamente o contrário, não só demonstraram muito interesse, como também interagiram nas discussões. Muitos participantes, inclusive, revelaram em seus depoimentos que a teoria foi de bastante relevância para o desenvolvimento da prática. Para inspirá-los nessa atividade, em específico, foram apresentados dois vídeos ${ }^{2}$ de coleções que envolvem o mesmo processo criativo que iriam experimentar.

Ao final da introdução teórica, foram passadas as instruções para a prática dos “Origamis vestiveis". Optou-se por trabalhar com algodão cru de boa qualidade, para que o tecido não fosse um agente limitador do processo. É importante nesses primeiros contatos com a experimentação da criação em moulage, eliminar empecilhos desnecessários para a prática. 0 uso de um bom manequim e melhor matéria-prima podem contribuir para o exercício fluir de maneira mais satisfatória. Dessa maneira, quando o participante se familiarizar com a experiência, será possível diversificar o experimento fazendo-se uso de materiais diversos (plástico, papel, couro...) e, até mesmo, remodelando o manequim com a técnica da bourrage, assim definida por Yamashita:

A técnica trata do estofamento e preenchimento do busto, moldando o seu formato e

2- Disponíveis em: <https://www.youtube.com/watch?v=n7-ZXVXcw00>; $<$ https://www.youtube.com/watch?v=_u2DL3CUJsw>, respectivamente. Acesso em: 18 fev. 2013. colocando-o nas medidas do corpo vivo do qual será o representante, [...]. A execução da bourrage está intrinsecamente ligada ao processo de criação, na consecução do conceito trabalhado, volume e caimento, principalmente quando não está vinculada às formas naturais de um corpo vivo e às tendências de mercado. (YAMASHITA, 2008, p. 5).

Ainda sobre tornar esse processo criativo mais agradável, é importante acrescentar a necessidade de se criar uma boa atmosfera para a prática. Nesse sentido, pode-se considerar a imensa relevância do uso de música durante o exercício. No caso do experimento referido neste artigo, foi possível visualizar importantes diferenças nas características das salas nas quais não foi usado esse recurso. Nas duas turmas onde não foi permitido o uso de música, observou-se que, em geral, os participantes se apresentaram mais inquietos e menos concentrados, sendo necessárias várias intervenções do ministrante na tentativa de destravar o processo, o que, aparentemente, influenciou diretamente nos resultados.

Nas salas com música, os participantes terminaram seus exercícios mais rapidamente e os resultados apresentaram uma carga de inovação e personalidade mais expressiva. Estas são observações subjetivas dos autores, aqui citadas por serem consideradas de alguma relevância para a pesquisa, mas não correspondem a dados conclusivos, uma vez que seriam necessários mais estudos e observações para se avaliarem esses aspectos. 0 estilo de musica escolhido para contribuir na ambientação para a atividade foi instrumental contemporâneo (Yann Tiersen, Ólafur Arnalds, Nils Frahm e Sigur Rós).

Também foi permitido que os participantes ouvissem música de sua escolha em seus próprios aparelhos, com fones de ouvidos. É importante salientarmos que o som deve estar em baixo volume, para não atrapalhar nas orientações que são dadas durante o acompanhamento do processo dos participantes. No decorrer de toda a atividade, os participantes são instruídos 
a terem atenção com as partes que, normalmente, não estão presentes no manequim de moulage, como cabeça e membros, a fim de não criarem uma peça que não possa vestir um corpo padrão. Também são orientados sobre a maneira correta de prender os alfinetes, tecido no tecido, usando a plataforma apenas como suporte, para que consigam retirar a peça do manequim ao fim da prática, possibilitando analisar o seu comportamento fora da plataforma de três dimensões e, até mesmo, experimentá-la em um corpo real.

Nos quatro primeiros workshops, permitiu-se que cada participante escolhesse a forma geométrica com a qual gostaria de trabalhar. Nesse caso, percebeu-se que, aproximadamente, $90 \%$ dos participantes optaram pela forma retangular. Observou-se que os participantes acreditavam ser mais fácil, inclusive, cortar esta forma, aproveitando a própria largura do tecido. Apesar de a grande maioria ter usado a base retangular como ponto de partida para as criações, os participantes alcançaram resultados bastante diversos e interessantes em termos criativos (figura 2). Partindo dessas observações, decidiu-se por realizar algumas modificações a serem aplicadas nos exercícios posteriores.

No quinto workshop foi adotada a estratégia de definir previamente a forma e medidas do tecido a serem adotadas por todos os participantes para que, dessa maneira, eles pudessem observar o quanto uma única forma pode gerar uma infınidade de resultados. Essa intervenção também possibilitou a experimentação de outras formas pelos participantes e aumentou o controle do ministrante sobre todo o processo, melhorando o desenvolvimento da atividade. Essa experiência

Figura 2 - Peças desenvolvidas pelos participantes dos workshops.

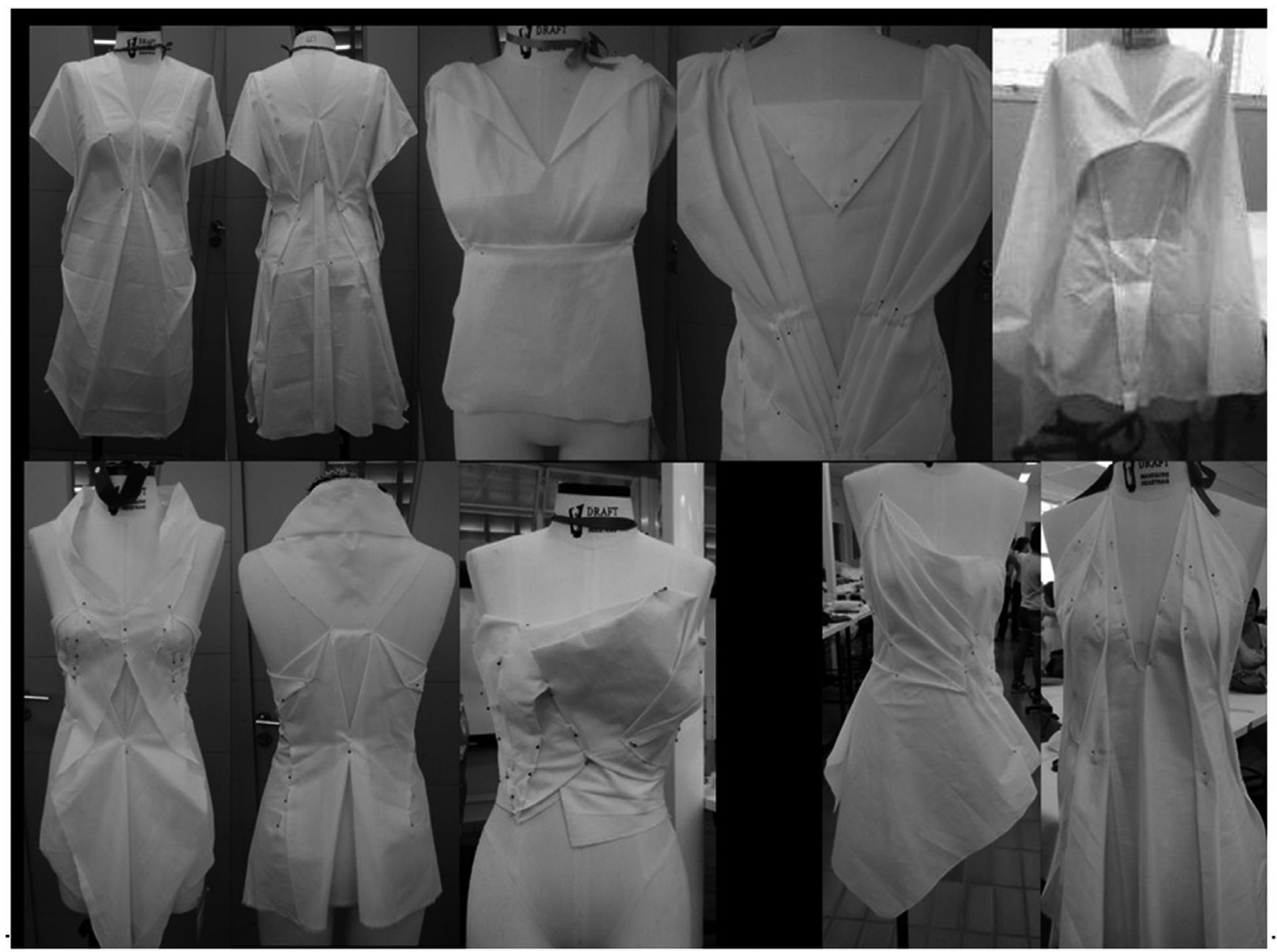

Fonte: Acervo próprio 
contribuiu tanto para aumentar a confiança por parte dos participantes nesse processo criativo, como também para ampliar o acervo de ideias. Os participantes eram sempre aconselhados a fotografar o seu processo e também a observar os trabalhos em volta, possibilitando a aprendizagem com as experiências dos outros.

No sexto e último workshop, que durou dois dias, com quatro horas de prática cada, além da estratégia de delimitar a mesma forma e medidas do tecido para todos, também foram adotados outros procedimentos que resultaram em ótimos desdobramentos para a mesma atividade. Por contar com mais tempo, foi possível aplicar a prática três vezes, sendo duas no primeiro dia. Para dar maior dinamicidade à atividade $\mathrm{e}$ promover a experimentação de diferentes graus de dificuldade, foram realizadas algumas mudanças. Para cada prática, foi determinada uma forma básica diferente, começando com o retângulo, depois o triângulo e, por fim, uma circunferência.
Com o retângulo, foi pedido que os participantes não cortassem o tecido em hipótese alguma, devendo obter uma peça de roupa apenas fazendo uso da manipulação do tecido sobre o manequim. Com o triângulo, além da manipulação, podiam fazer uso de recortes, contanto que não se retirasse nenhuma parte do tecido. Nesta prática, os participantes já deveriam inserir algum recorte aleatório no molde, antes mesmo de levarem o tecido ao manequim. Com a circunferência, foi proposto, além das regras do segundo exercício, um tema, que serviria para nortear a criação.

$\mathrm{Na}$ atividade, foi possivel notar que a forma que serviu de ponto de partida para o exercício de criação não influenciou diretamente nos resultados finais das peças criadas. De fato, o que se observa é que os resultados do processo de criação estão muito mais relacionados com a personalidade criativa de cada indivíduo. Esta característica pode ser visualizada na figura 3.

Figura 3 - Peças de um mesmo participante, cada uma partindo de um tecido em uma forma geométrica diferente (retângulo, triângulo e círculo, da esquerda para a direita).

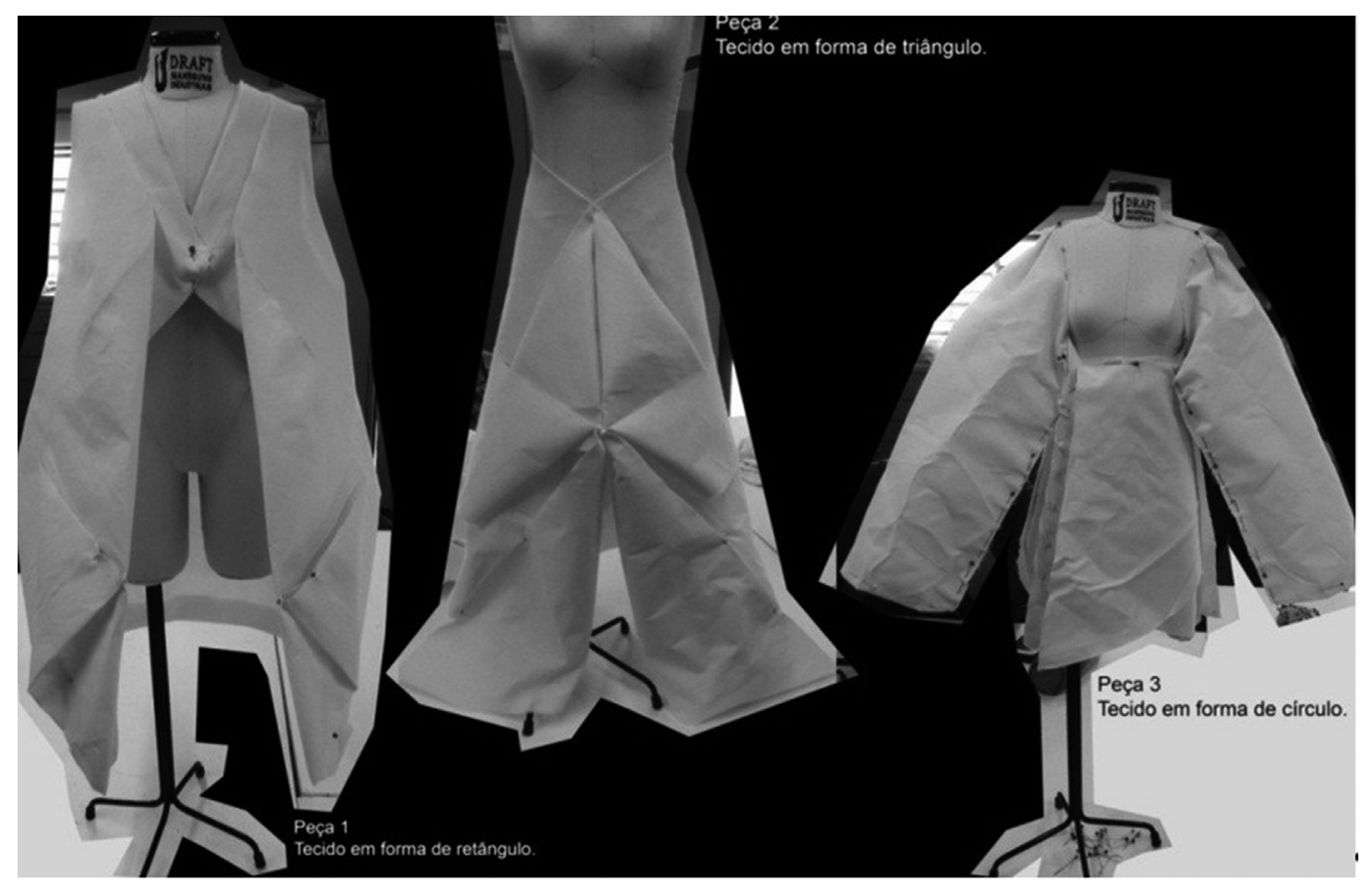

Fonte: Acervo próprio 
Quase a totalidade dos participantes conseguiu concluir os exercícios propostos em uma hora e meia de prática, em média. Mesmo os participantes que nunca tinham tido contato com a moulage ou técnica nenhuma de modelagem não apresentaram dificuldades relevantes, se comparados ao restante dos envolvidos.

\section{Conclusão}

Levando-se em conta os resultados obtidos neste experimento, no qual se observou um elevado nível de satisfação dos participantes e considerando a carência de material de apoio para o exercício de atividades desse gênero em sala de aula, os autores deste artigo ressaltam a relevância das informações aqui abordadas, mesmo se tratando de uma amostra de pouco mais de cinquenta participantes. É importante salientar que o intuito principal deste artigo é discutir e incentivar a experimentação de processos criativos no âmbito da educação universitária, de maneira integrada e contínua, adequando-se as demandas do meio e criando a estrutura necessária para que estas atividades façam parte da realidade dos cursos e não continuem sendo tratadas como experiências pontuais e de menos importância.

Durante todo o processo de aplicação das atividades com os participantes, foi possível visualizar o uso satisfatório da moulage como meio de expressão de ideias em vestuário, meio para a criação. Ao fim de cada atividade, os participantes não só aprendiam enquanto executavam seus próprios trabalhos, como também aprendiam uns com os outros, ampliando seus acervos de conhecimento.

Os resultados desta pesquisa apontam que a criação em moulage poderia ser mais explorada nos cursos voltados para profissionais da área de moda, como motivadora do conhecimento. Durante as atividades propostas, percebeu-se a grande satisfação que os participantes tiveram ao se surpreenderem com as suas próprias criações. Outro fator relevante a ser considerado é o elevado grau de concentração e motivação deles enquanto executavam os exercícios. A criação em moulage pode ser um meio para pensarmos uma nova postura perante a formação dos profissionais de moda, mais coerente com o que, atualmente, se espera de uma educação de ponta, pautada em valores humanos e nas potencialidades de cada indivíduo, preparando os alunos para o mundo que vai exigir deles não só o conhecimento técnico, mas também a capacidade de adaptação e improvisação.

0 perfil do potencial profissional de sucesso, atualmente, é aquele indivíduo que aprendeu pelos caminhos da vida a pensar por si só, a desvelar o mundo com os próprios olhos e a usar o conhecimento como um mediador de novas descobertas e não como a finalidade do aprendizado em si. É preciso que olhemos para essa realidade agora, para desenvolver esses preceitos na educação do presente e esperarmos que as consequências dessa postura mais consciente reflitam num futuro próspero para a nossa educação. 


\section{Referências}

BOLTON, Andrew. Alexander McQueen: savage beauty. New York. The Metropolitan Museun of Art, 2011.

NAKAMICHI, Tomoko. Patten magic 2. London: Laurence King, 2011.

ROBINSON, Ken. Bring on the learning revolution. In: TEDTalks, 2010, California. Anais eletrônicos... California: TED Conferences, LLC, 2010. Palestra. Disponível em: <http:// ted.com/talks/sir_ken_robinson_bring_on_the_revolution/transcript>. Acesso em: 03 dez. 2014.

SEELING, Charlotte. Moda: 0 século dos estilistas. Colônia: Konemann, 2000.

SOUZA, Patrícia de Melo. A modelagem tridimensional como implemento do processo de desenvolvimento do produto de moda. 2006. Dissertação (Mestrado) - Universidade Estadual Paulista "Júlio de Mesquita Filho" Unesp, Bauru, 2006.

SOUZA, Patrícia de Melo. Estratégias de construção para estruturas têxteis. 2013. Tese (Doutorado em Design) - Faculdade de Arquitetura, Artes e Comunicação da Universidade Estadual Paulista “Júlio de Mesquita Filho" Unesp, Bauru, 2013.

SUASSUNA, Ariano. Iniciação a estética. Recife: UFPE, 1975.

VASARI, Giorgio. A vida dos mais excelentes pintores, escultores e arquitetos. In: LICHTENSTEIN, Jacqueline. A pintura: 0 desenho e a cor. v. 9. São Paulo: 34, 2006. Organização e apresentação de Jacqueline Lichtenstein. Coordenação da tradução de Magnólia Costa.

WOLFF, Colette. The art of manipulating fabric. Wisconsin: Krause, 1996.

YAMASHITA, Yaeko. A moulage como processo criativo do estilista contemporâneo. In: COLÓQUIO DE MODA, 4., 2008, Novo Hamburgo. Anais... Novo Hamburgo: FEEVALE, 2008. CD-R00M.

Recebido em: 08.09.2014

Aprovado em: 14.04.2015

Jonathan Gurgel de Lima é mestre em têxtil e moda pela Universidade de São Paulo (USP). Professor do programa de pósgraduação em modelagem e moulage no processo de criação no SENAC Lapa Faustolo - SP.

Isabel Cristina Italiano é professora do curso de bacharelado em têxtil e moda e do programa de pós-graduação em têxtil e moda da Universidade de São Paulo (USP). 